\title{
Effect of Leg Crossing and Hand Griping Techniques on Reducing Vasovagal Symptoms Associated with Vein Puncture in Pediatric Patients
}

Reda Abdel-Mohsen Mahmoud Awd ${ }^{1}$, Wafaa El-Sayed Ouda ${ }^{2}$, Faten Shafik Mahmoud ${ }^{3}$, and Hanan Nabawy El-Aasar ${ }^{4}$

(1) Assistant lecturer of Pediatric Nursing, Faculty of Nursing, Benha University, Egypt, (2) Professor of Pediatric Nursing, Faculty of Nursing - Ain Shams University, Egypt, (3) Professor of Pediatric Nursing, Faculty of Nursing, Benha University, Egypt and (4) Assist. Prof of Pediatric Nursing, Faculty of Nursing, Benha University, Egypt

\section{Abstract}

Background: Leg crossing and hand griping techniques appear to have an immediate beneficial effect on decreasing vasovagal symptoms. Aim of this study: Was to evaluate the effect of leg crossing and hand griping techniques on reducing vasovagal symptoms associated with vein puncture in pediatric patients. Research design: A quasi experimental design was utilized in this study. Setting: This study was conducted at emergency department and inpatient pediatric department at both Benha Teaching Hospital and Benha University Hospital. Sample: A purposive sample of children (90) was selected. A simple random sample was used to assign the children into three equal groups according to type of intervention: Leg crossing group, Hand gripping group and control group. Tools of data collection: Three tools were used I): A structured interviewing questionnaire to assess characteristics of studied children, Their medical data, Physiological measurements and assessment of common vasovagal signs and symptoms associated with vein puncture pre and post intervention), II): Children's Fear Scale and III): Children's satisfaction questionnaire sheet. Results: There were highly significant differences between groups of the study in relation to total vasovagal signs and symptoms associated with vein puncture and fear assessment in groups of the study pre and post technique implementation $(p=<0.01)$. Children in the study groups were satisfied with the implemented techniques for its effect on reducing vasovagal symptoms associated with vein puncture. Conclusion: Leg crossing and handgrip techniques were associated with decrease in vasovagal symptoms of children undergoing vein puncture and experienced fewer numbers of vasovagal symptoms as compared to children in control group. Children in study groups were satisfied with the implemented techniques for its effect on reducing vasovagal symptoms associated with vein puncture. Recommendations: Leg crossing and hand griping techniques can be integrated as a part of routine daily care for children who had a past history of vasovagal symptoms associated with vein puncture.

Key words: Leg crossing, Hand griping techniques, Vasovagal symptoms, Vein puncture, Pediatric patients.

\section{Introduction}

Syncope caused by transient ischemia of the brain, is a transient disturbance of consciousness and often accompanied by loss of autonomic muscle tone. As a common disorder in children and adolescents, syncope usually occurs quickly and spontaneously, lasting from a few seconds to a few minutes.

It has been reported that $20 \%-30 \%$ of the children and adolescents aged from 5 to 18 years old have experienced at least one syncope, and about $50 \%$ of these syncope children are Vasovagal Syncope (VVS). The VVS is a temporary loss of consciousness that caused by the dysfunction of autonomic 
nervous system due to various reasons and it can lead to the decrease of blood pressure, heart rate, hypoxia and cerebral hypo perfusion (Zhang et al., 2020).

A sudden loss of consciousness in a child can cause anxiety amongst both parents and clinicians. It presents in various forms, such as fainting, black outs, collapse, and passing out. Vasovagal reflex syncope may occur at all ages, especially in children and adolescents. Some studies indicated that the incidence of syncope in the pediatric age that requires medical intervention is estimated around $1 \%$ of toddlers may have a form of vasovagal syncope, the risk increasing with age and peaking at around 15 years old. The incidence of syncope requiring medical attention is $125 / 100,000$ that is up to $47 \%$ of adolescent girls and $24 \%$ of adolescent boys. It accounts for $3 \%$ of emergency department attendances and $1 \%$ of all hospital admissions (Naganna et al., 2020).

Vasovagal syncope typically results from a specific trigger that increases parasympathetic tone and decreases sympathetic tone. Common triggers include emotional stress, pain, trauma, being in a crowded or warm environment, or phobias such as to blood or needles. Often, these triggers are potentiated by hunger, exhaustion, intercurrent illness, and orthostatic stress, such as from hypovolemia, prolonged standing, and/or positional changes. Characteristically, there is a prodrome of symptoms lasting seconds to minutes secondary to activation of the autonomic nervous system. Common symptoms include gastrointestinal upset or abdominal pain, nausea, sweating, pallor, general weakness, lightheadedness, or tunnel vision (Dalton\& Wang, 2017).
Current practice when pediatric patients report a history of vasovagal symptoms includes having children lie down and instituting safety precautions in anticipation of possible syncope. While these interventions increase children safety, they do not attempt to prevent the syncope symptoms from occurring. Many studies have observed interventions to decrease or prevent vasovagal symptoms in adult patients. Increased dietary salt intake and counter-pressure techniques were recommended as one of the first-line nonpharmacological treatment measures (Fathalla\& Ghoneim, 2018).

The pediatric nurse should provide children with reassurance and education regarding the nature, risks, and prognosis of the condition. Children education involves recognition of the potential symptoms and actions to take upon recognition of any early warning signs as well as identification of potential triggers. Children should be advised to assume the supine position with legs raised at the onset of symptoms, whenever feasible. For children with vasovagal syncope, pediatric nurses recommend physical isometric maneuvers such as Legcrossing with simultaneous tensing of leg, abdominal, and buttock muscles and Handgrip, which consists of maximum grip on a rubber ball or similar object (Shen et al., 2017; Brignole et al., 2018).
Aim of the study
The aim of this study was to evaluate the effect of leg crossing and hand griping techniques on reducing vasovagal symptoms associated with vein puncture in pediatric patients. 


\section{Reda Abdel-Mohsen, Wafaa El-Sayed, Faten Shafik andHanan Nabawy}

\section{Research hypothesis:}

1- Children who participate in leg crossing and hand griping techniques would experience fewer vasovagal symptoms as compared with children who will only receive routine care during vein puncture.

2- Children who participate in leg crossing and hand griping techniques would be more satisfied with the implemented techniques for its effect on reducing vasovagal symptoms associated with vein puncture.

\section{Subject and Methods}

Research design:

A quasi -experimental research design was utilized to conduct the study.

\section{Setting:}

This study was conducted at emergency department and inpatient pediatric department at both Benha University Hospital affiliated to university and Benha Teaching Hospital affiliated to ministry of health and population.

\section{Sample:}

A purposive sample of children (90) having venous access for any reason as blood sample, or intravenous placement over 6 months period from the previously mentioned settings. A simple random sample was used to assign children into three groups: Leg crossing group (30), Hand gripping group (30) and control group (30). Children in the control group only received only routine department care.

\section{Tools for data collection:}

Tool I:- A structured interviewing questionnaire: It was developed by the researcher in an Arabic language after reviewing the recent relevant literature to gather data required to assess vasovagal symptoms associated with vein puncture and it was composed of four parts:
- Part (1): Characteristics of the studied children such as: - age, gender, educational stage, birth order \& residence. It contained of (five questions)

\section{-Part (2): Medical Data of Children}

A- Medical history of the child which was checked from medical file of the child such as: - diagnosis, duration of stay in hospital and past hospitalization (three questions).

B- Data related to vein puncture such as site, reason and problems associated with vein puncture (three questions).

\section{- Part (3): Physiological measurements of} the studied Children:

It consisted of vital signs that were measured just before and after vein puncture (children's heart rate, respiration rate and blood pressure) and compared with their normal peers.

-Part (4): Assessment of common vasovagal signs and symptoms associated with vein puncture pre and post technique implementation such as light-headedness, dizziness, dilated pupils, blurred vision, seeing black dots, a slow, weak pulse, salivation, nausea, vomiting, abdominal discomfort, sudden urge to defecate, pallor, sweating/diaphoresis, sighing \& pale skin.

\section{Tool II: Children's Fear Scale (CFS).}

The CFS scale was adopted from McMurtry et al., (2011) to measure fear level in children. This scale consisted of a raw of five neutral faces ranging from a no fear face on the far left to a face showing extreme fear on the far right. Scores on the CFS were converted to numerical scores and the total score is ranging from $0-4$.

\section{Scoring system for children fear scale:}

Scoring system was used to divide fear into four levels namely: no fear (zero), mild fear (1), moderate fear (2), severe fear (3) and extremely fear (4). 


\section{Effect of Leg Crossing and Hand Griping Techniques on Reducing Vasovagal Symptoms}

\section{Associated with Vein Puncture in Pediatric Patients}

\section{Tool III: Children's satisfaction questionnaire sheet:}

It was developed by the researcher after reviewing scientific literature. Children responses were classified into three categories to assess children's satisfaction level regarding the effect of leg crossing and hand griping techniques on reducing vasovagal symptoms during vein puncture.

\section{Content validity:}

Validity of the tools was checked by a jury of three experts (professor and two assistant professors) in pediatric nursing to test face and content validity. The experts reviewed the tools for clarity, relevance, comprehensiveness, simplicity and applicability. The jury comments were considered regarding the format, layout, paraphrasing, consistency, accuracy and relevancy of the tools. Then the final form was used in data collection.

\section{Reliability:}

Reliability of the tools was checked by testing its internal consistency using Cronbach's alpha coefficient test. Where $\mathrm{a}=$ 0.71 for questionnaire $a=0.87$ for fear scale and $a=0.84$ for children satisfaction questionnaire sheet. So tools were found to be highly reliable for data collection.

\section{Ethical considerations}

Ethical approval was obtained from scientific research ethical committee in Faculty of Nursing Benha University, hospital administrator and head of department inpatient pediatric department at both Benha Teaching Hospital affiliated to ministry of health and population and Benha University Hospital affiliated to university before starting the study and ensured each participant approval was involved in the study before collection of any data and after explanation of the aim of the study in simple and clear manner. The study subjects (and their accompanying parents) were informed that the study is harmless. The privacy was maintained and oral consent was taken for participation. Their inclusion in the study was voluntary. They were allowed to quit at any time and confidentiality of the gathered data were secured. Children's norms, believes and habits were taken into consideration.

\section{Pilot study}

Pilot study was carried out on $10 \%$ (9 children) of the expected sample size to check the clarity, applicability, and feasibility of the study tools. The necessary modifications were done accordingly. The children included in the pilot study were not excluded from the study as no radical modifications were done in the study tool.

\section{Field work:}

Data collection for this study was conducted for a period of 6 months starting from the first of June to the end of November 2020.Data was collected two days weekly (Saturday \& Tuesday) from 8A.M to 10 A.M, from the emergency department and inpatient pediatric department at Benha University Hospital. In Benha Teaching Hospital, data was collected on Monday \& Thursday from 8A.M to 10 A.M. Data was collected by using previously mentioned tools.

The researcher explained the nature and purpose of the study to nurses who were working in the previously mentioned

All studied children (study and control groups) received routine vein puncture protocol during vein puncture. 


\section{$\underline{\text { Reda Abdel-Mohsen, Wafaa El-Sayed, Faten Shafik andHanan Nabawy }}$}

Physiological measurements (heart rate, respiration and blood pressure) were assessed for each child just before and after vein puncture. In the Control group, children only received routine care. Children in this group were assessed by the researcher during vein puncture procedure without any intervention from the researcher. After finishing data collection from the control group, data was collected from the study group.

The researcher interviewed each child individually using the previously mentioned tools (10 minutes). Then, each child was taught individually about how to perform leg crossing and handgrip techniques. This included breaking down the technique into simple steps and using visual images to explain the techniques. The researcher helped children to practise the techniques many times prior to vein puncture to ensure that children can do techniques effectively and efficiently as the following:

Leg crossing technique was conducted as follows.

Children were placed in supine position with head of the bed slightly elevated during venipuncture.

Each child had to cross his/her legs at the ankles.

- $\quad$ Each child was asked to squeeze buttocks together.

- $\quad$ The child was asked to take deep breathing while keeping arms relaxed.

- $\quad$ The researcher was ensured previous steps were done during vein puncture.

Handgrip technique was conducted as follows

The child was asked to holds a rubber ball in the hand that is used for writing.
This rubber ball is squeezed as long as the child can or until symptoms disappear

The researcher was ensured two previous steps were done during vein puncture.

Children were allowed to practice the techniques at the same time; the researcher assessed vasovagal symptoms, their fear of vein puncture and satisfaction with the implemented techniques.

\section{Statistical analysis:}

Data entry and statistical analysis were done using SPSS 21.0 statistical software package.

\section{Results:}

Table (1): Shows that there was no statistical significant difference in characteristics of the studied children $(\mathrm{p}=>0.05)$. As noticed, half and more than half $(50 \%, 56.6 \%$ and $50 \%)$ of the studied children ranged from $8-<10$ years. Also, around two thirds (60\%, 66.7\% and $73.3 \%$ ) of them were males. Moreover, around two thirds $(60 \%, 66.7 \%$ and $60 \%)$ of them were at primary school. Also, half and more than half $(63.3 \%, 50 \%$ and $53.3 \%)$ of them were living in urban areas.

Table (2): Indicates that there was no statistical significant difference in medical data of studied children ( $\mathrm{p}=>0.05)$. Most $(80 \%, 86.7 \%$ and $83.3 \%)$ of them had hand vein puncture for intravenous cannulation. Also, more than two thirds had previous fainting episodes $(73.3 \%, 80 \%$, and 86.7$)$. Approximately one third $(33.3 \%, 40 \%$ and $33.3 \%$ ) of them had pain at the puncture site.

Table (3): Reveals that there was a highly statistical significant difference between physiological measurements of leg crossing group, griping group and control group immediately, before and after vein puncture 
Table (4): Shows that there was a highly statistical significant difference between leg crossing group, gripping group and control group related to all vasovagal signs and symptoms pre and post technique implementation $(\mathrm{p}=<0.01)$.

Table (5): Reveals that there was a highly statistical significant difference between leg crossing, griping and control groups due to fear level pre and post technique implementation $(\mathrm{p}=<0.01)$. As noticed, $46.6 \%$ of the leg crossing group were extremely fearful pre technique implementation. While, $66.7 \%$ of them had no fear at post technique implementation. Also, $40 \%$ of the hand griping group were extremely fearful pre technique implementation. While, $60 \%$ of them had no fear post technique implementation. Moreover, $40 \%$ of the control group were extremely fearful pre intervention. Also, $33.3 \%$ of them were extremely fearful at post intervention.

Figure (1): Indicates that most $(86.7 \%)$ of the hand griping group were very satisfied about hand gripping technique. While, $13.3 \%$ of them were little satisfied.

Figure (2): Reveals that the majority (90\%) of children in the leg crossing group were very satisfied about leg crossing technique. While, $10 \%$ of them were little satisfied. 
Reda Abdel-Mohsen, Wafaa El-Sayed, Faten Shafik andHanan Nabawy

Table (1): Distribution of the studied children according to their personal characteristics $(\mathbf{n}=$ 90)

\begin{tabular}{|c|c|c|c|c|c|c|c|c|}
\hline \multirow{3}{*}{$\begin{array}{l}\begin{array}{c}\text { Characteristics of studied } \\
\text { children }\end{array} \\
\text { Age in years }\end{array}$} & \multirow{2}{*}{\multicolumn{2}{|c|}{$\begin{array}{l}\text { Leg } \\
\text { crossing } \\
\text { group } \\
(\mathbf{n}=\mathbf{3 0})\end{array}$}} & \multirow{2}{*}{\multicolumn{2}{|c|}{$\begin{array}{l}\text { Hand } \\
\text { griping } \\
\text { group } \\
(\mathrm{n}=30)\end{array}$}} & \multirow{2}{*}{\multicolumn{2}{|c|}{$\begin{array}{l}\text { Control } \\
\text { group } \\
(n=30)\end{array}$}} & \multicolumn{2}{|c|}{$\begin{array}{c}\text { Friedman } \\
\text { test }\end{array}$} \\
\hline & & & & & & & $\mathrm{X}^{2}$ & $\begin{array}{c}P \\
\text { value }\end{array}$ \\
\hline & No & $\%$ & No & $\%$ & No & $\%$ & & \\
\hline $8:<10$ & 15 & 50 & & 56.6 & 15 & 50 & & \\
\hline $10:<12$ & 8 & 26.7 & 7 & 26.7 & 10 & 33.3 & & \\
\hline $12:<15$ & 4 & 13.3 & & 10 & 3 & 10 & 1.627 & .903 \\
\hline $15: \leq 18$ & 3 & 10 & & 6.7 & 2 & 6.7 & & \\
\hline S.D $\bar{x} \pm$ & \multicolumn{2}{|c|}{$10.7 \pm 2.34$} & \multicolumn{2}{|c|}{$10.4 \pm 3.60$} & \multicolumn{2}{|c|}{$11.3 \pm 2.91$} & & \\
\hline \multicolumn{7}{|l|}{ Gender } & \multirow{3}{*}{.963} & \multirow{3}{*}{4.360} \\
\hline Male & 18 & 60 & 20 & 66.7 & 22 & 73.3 & & \\
\hline Female & 12 & 40 & 10 & 33.3 & 8 & 26.7 & & \\
\hline \multicolumn{7}{|l|}{ Educational level } & \multirow{4}{*}{1.347} & \multirow{4}{*}{.985} \\
\hline Primary & 18 & 60 & 20 & 66.7 & 18 & 60 & & \\
\hline Preparatory & 9 & 30 & 8 & 26.7 & 10 & 33.3 & & \\
\hline Secondary & 3 & 10 & 2 & 6.7 & 2 & 6.7 & & \\
\hline \multicolumn{7}{|c|}{ Rank of the child between his siblings } & \multirow{4}{*}{1.530} & \multirow{4}{*}{.891} \\
\hline $1^{\text {st }}$ & 14 & 46.6 & 18 & 60 & 16 & 53.3 & & \\
\hline 2nd & 8 & 26.7 & 7 & 23.3 & 9 & 30 & & \\
\hline $3^{\text {rd }}$ & 8 & 26.7 & 5 & 16.7 & 5 & 16.7 & & \\
\hline \multicolumn{7}{|l|}{ Residence } & \multirow{3}{*}{1.792} & \multirow{3}{*}{.541} \\
\hline Rural & 11 & 36.7 & 15 & 50 & 14 & 46.7 & & \\
\hline Urban & 19 & 63.3 & 15 & 50 & 16 & 53.3 & & \\
\hline
\end{tabular}


Effect of Leg Crossing and Hand Griping Techniques on Reducing Vasovagal Symptoms Associated with Vein Puncture in Pediatric Patients

Table (2): Distribution of the studied children according to their medical data related to vein puncture $(\mathbf{n}=90)$

\begin{tabular}{|c|c|c|c|c|c|c|c|c|}
\hline $\begin{array}{l}\text { Medical data of the studied } \\
\text { children data to vein puncture }\end{array}$ & \multicolumn{2}{|c|}{$\begin{array}{l}\text { Leg crossing } \\
\text { group } \\
(n=30)\end{array}$} & \multicolumn{2}{|c|}{$\begin{array}{c}\text { Hand } \\
\text { griping } \\
\text { group } \\
(n=30)\end{array}$} & \multicolumn{2}{|c|}{$\begin{array}{l}\text { Control } \\
\text { group }\end{array}$} & \multicolumn{2}{|c|}{$\begin{array}{c}\text { Friedman } \\
\text { test }\end{array}$} \\
\hline \multicolumn{7}{|l|}{ Location of vein puncture } & \multirow{4}{*}{1.806} & \multirow{4}{*}{.630} \\
\hline Hand & 24 & 80 & 26 & 86.7 & 25 & 83.3 & & \\
\hline Foot & 4 & 13.3 & 3 & 10 & 5 & 16.7 & & \\
\hline Skull & 2 & 6.7 & 1 & 3.3 & 0 & 0.0 & & \\
\hline Indications of vein puncture & & & & & & & \multirow{3}{*}{.953} & \multirow{3}{*}{2.370} \\
\hline Intravenous cannulation & 25 & 83.3 & 25 & 83.3 & 22 & 73.3 & & \\
\hline Taking a blood sample & 5 & 16.7 & 5 & 16.7 & 8 & 26.7 & & \\
\hline \multicolumn{7}{|c|}{ Problems associated with vein puncture * } & \multirow{7}{*}{1.520} & \multirow{7}{*}{.7463} \\
\hline Fainting & 22 & 73.3 & 24 & 80 & 26 & 86.7 & & \\
\hline Pain at the puncture site & 10 & 33.3 & 12 & 40 & 10 & 33.3 & & \\
\hline Redness of the puncture site & 8 & 26.7 & 6 & 20 & 4 & 13.3 & & \\
\hline Swelling & 4 & 13.3 & 2 & 6.7 & 2 & 6.7 & & \\
\hline Venous leak & 3 & 10 & 2 & 6.7 & 3 & 10 & & \\
\hline Nothing & 5 & 16.7 & 8 & 26.7 & 11 & 36.7 & & \\
\hline
\end{tabular}


Reda Abdel-Mohsen, Wafaa El-Sayed, Faten Shafik andHanan Nabawy

Table (3): Mean and standard deviation of physiological measurements of the studied children in the groups of the study immediately before and after vein puncture $(n=90)$.

\begin{tabular}{|c|c|c|c|c|c|c|c|c|}
\hline \multirow{4}{*}{$\begin{array}{l}\text { Physiological } \\
\text { measurements }\end{array}$} & \multirow{2}{*}{\multicolumn{2}{|c|}{$\begin{array}{l}\text { Leg crossing group } \\
\qquad(\mathrm{n}=30)\end{array}$}} & \multirow{2}{*}{\multicolumn{2}{|c|}{$\begin{array}{l}\text { Hand griping group } \\
(\mathrm{n}=30)\end{array}$}} & \multirow{2}{*}{\multicolumn{2}{|c|}{$\begin{array}{c}\text { Control group } \\
(\mathbf{n}=\mathbf{3 0})\end{array}$}} & \multicolumn{2}{|c|}{ Anova test } \\
\hline & & & & & & & \multirow[t]{3}{*}{ t. test } & \multirow{3}{*}{$\begin{array}{c}\mathbf{P} \\
\text { value }\end{array}$} \\
\hline & Pre & Post & Pre & Post & Pre & Post & & \\
\hline & $\overline{S . D \bar{x} \pm}$ & S.D $\bar{x} \pm$ & $\overline{S . D \bar{x} \pm}$ & $\overline{S . D \bar{x} \pm}$ & $\overline{\text { S.D } \overline{\boldsymbol{x}} \pm}$ & $\overline{S . D \bar{x}} \pm$ & & \\
\hline Heart rate & $50.5 \pm 4.3$ & $73.9 \pm 0.93$ & $51.3 \pm 3.9$ & $75.4 \pm 1.03$ & $52.2 \pm 4.6$ & $55.9 \pm 3.8$ & 20.31 & $.000 * *$ \\
\hline Respiration & $25.5 \pm 6.34$ & $14 \pm 0.99$ & $24.9 \pm 4.28$ & $13.5 \pm 0.91$ & $23.4 \pm 5.5$ & $20.8 \pm 3.95$ & 22.87 & $.000 * *$ \\
\hline $\begin{array}{l}\text { Blood } \\
\text { pressure: } \\
\text { Systolic }\end{array}$ & $100.3 \pm 5.3$ & $110.5 \pm 1.9$ & $101.8 \pm 7.6$ & $110.5 \pm 1.9$ & $99.3 \pm 5.7$ & $101.4 \pm 4.5$ & 18.94 & $.000 * *$ \\
\hline Diastolic & $58.7 \pm 6.4$ & $81.3 \pm 1.7$ & $60.5 \pm 5.5$ & $80.7 \pm 2.1$ & $61.5 \pm 4.9$ & $65.2 \pm 4.1$ & 19.06 & $.000 * *$ \\
\hline
\end{tabular}

Highly significant $\mathbf{P}<0.001 * *$

Significant $\mathbf{P}<0.05 *$

Table (4): Percentage distribution regarding the presence of common vasovagal signs and symptoms in groups of the study pre and post technique implementation $(n=90)$.

\begin{tabular}{|l|c|c|c|c|c|c|c|}
\hline \multirow{2}{*}{$\begin{array}{c}\text { Vasovagal signs and } \\
\text { symptoms }\end{array}$} & \multicolumn{2}{|c|}{$\begin{array}{c}\text { Leg crossing } \\
\text { group } \\
\text { (n=30) }\end{array}$} & \multicolumn{2}{c|}{$\begin{array}{c}\text { Hand griping } \\
\text { group } \\
(\mathbf{n = 3 0 )}\end{array}$} & \multicolumn{2}{c|}{$\begin{array}{c}\text { Control group } \\
(\mathbf{n = 3 0 )}\end{array}$} & $\begin{array}{c}\text { Friedman } \\
\text { test } \\
\text { P value }\end{array}$ \\
\cline { 2 - 7 } & Pre & Post & Pre & Post & Pre & Post & \\
\hline Light-headedness & 60 & 13.3 & 53.3 & 13.3 & 66.7 & 56.7 & $.000^{* *}$ \\
\hline Dizziness & $\mathbf{7 3 . 3}$ & $\mathbf{0 . 0}$ & $\mathbf{6 6 . 7}$ & $\mathbf{6 . 7}$ & $\mathbf{6 0}$ & 50 & $.000^{* *}$ \\
\hline Dilated pupils & 40 & 6.7 & 33.3 & 6.7 & 33.3 & 26.7 & $.001^{* *}$ \\
\hline Blurred vision & 46.7 & 6.7 & 40 & 0.0 & 40 & 33.3 & $.000^{* *}$ \\
\hline Seeing black dots & 26.7 & 6.7 & 16.7 & 00.0 & 20 & 16.7 & $.005^{* *}$ \\
\hline A slow, weak pulse & $\mathbf{8 6 . 7}$ & $\mathbf{1 3 . 3}$ & $\mathbf{8 0}$ & $\mathbf{1 3 . 3}$ & $\mathbf{7 3 . 3}$ & 66.7 & $.000^{* *}$ \\
\hline Salivation & 26.7 & 6.7 & 26.7 & 6.7 & 33.3 & 33.3 & $.000^{* *}$ \\
\hline Nausea & 60 & 6.7 & 50 & 6.7 & 60 & 50 & $.000^{* *}$ \\
\hline Vomiting & 26.7 & 6.7 & 20 & 0.0 & 33.3 & 26.7 & $.000^{* *}$ \\
\hline Abdominal discomfort & 26.7 & 6.7 & 20 & 0.0 & 33.3 & 26.7 & $.000^{* *}$ \\
\hline Sudden urge to defecate & 13.3 & 0.0 & 6.7 & 0.0 & 13.3 & 13.3 & $.007^{* *}$ \\
\hline Pallor & 73.3 & 0.0 & 66.7 & 6.7 & 60 & 50 & $.000^{* *}$ \\
\hline Sweating/ & 73.3 & 13.3 & 66.7 & 6.7 & 60 & 50 & $.000^{* *}$ \\
\hline Diaphoresis & 26.7 & 6.7 & 23.3 & 0.0 & 36.7 & 33.3 & $.000^{* *}$ \\
\hline Sighing & $\mathbf{8 0 \%}$ & $\mathbf{6 . 7 \%}$ & $\mathbf{6 6 . 7}$ & $\mathbf{6 . 7}$ & $\mathbf{6 6 . 7}$ & 46.7 & $.000^{* *}$ \\
\hline Pale skin & & & & &
\end{tabular}

Highly significant $\mathbf{P}<0.001 * *$

Significant $\mathbf{P}<0.05 *$ 
Effect of Leg Crossing and Hand Griping Techniques on Reducing Vasovagal Symptoms Associated with Vein Puncture in Pediatric Patients

Table (5): Percentage distribution of the studied children in groups of the study according to their fear level at pre- and post- technique implementation $(\mathbf{n}=90)$

\begin{tabular}{|c|c|c|c|c|c|c|c|c|}
\hline \multirow[t]{2}{*}{ Items } & \multicolumn{2}{|c|}{$\begin{array}{l}\text { Leg crossing } \\
\text { group } \\
(\mathbf{n}=30)\end{array}$} & \multicolumn{2}{|c|}{$\begin{array}{l}\text { Hand griping } \\
\text { group } \\
(\mathbf{n}=\mathbf{3 0})\end{array}$} & \multicolumn{2}{|c|}{$\begin{array}{l}\text { Control group } \\
\qquad(n=30)\end{array}$} & \multicolumn{2}{|c|}{ Friedman test } \\
\hline & Pre & Post & Pre & Post & Pre & Post & $\mathbf{X}^{2}$ & $\begin{array}{c}P \\
\text { value }\end{array}$ \\
\hline No fear & $(0.0)$ & 66.7 & $(0.0)$ & 60 & $(0.0)$ & 6.7 & \multirow{5}{*}{26.34} & \multirow{5}{*}{$.000 * *$} \\
\hline Mild fear & 6.7 & 23.3 & 10 & 26.7 & 6.7 & 16.7 & & \\
\hline Moderate fear & 16.7 & 10 & 23.3 & 13.3 & 26.7 & 16.7 & & \\
\hline Severe fear & 30 & $(0.0)$ & 26.7 & $(0.0)$ & 26.6 & 26.6 & & \\
\hline Extremely fearful & 46.6 & $(0.0)$ & 40 & $(0.0)$ & 40 & 33.3 & & \\
\hline
\end{tabular}

Highly significant $\mathrm{P}<0.001 * *$

Significant $\mathrm{P}<0.05 *$

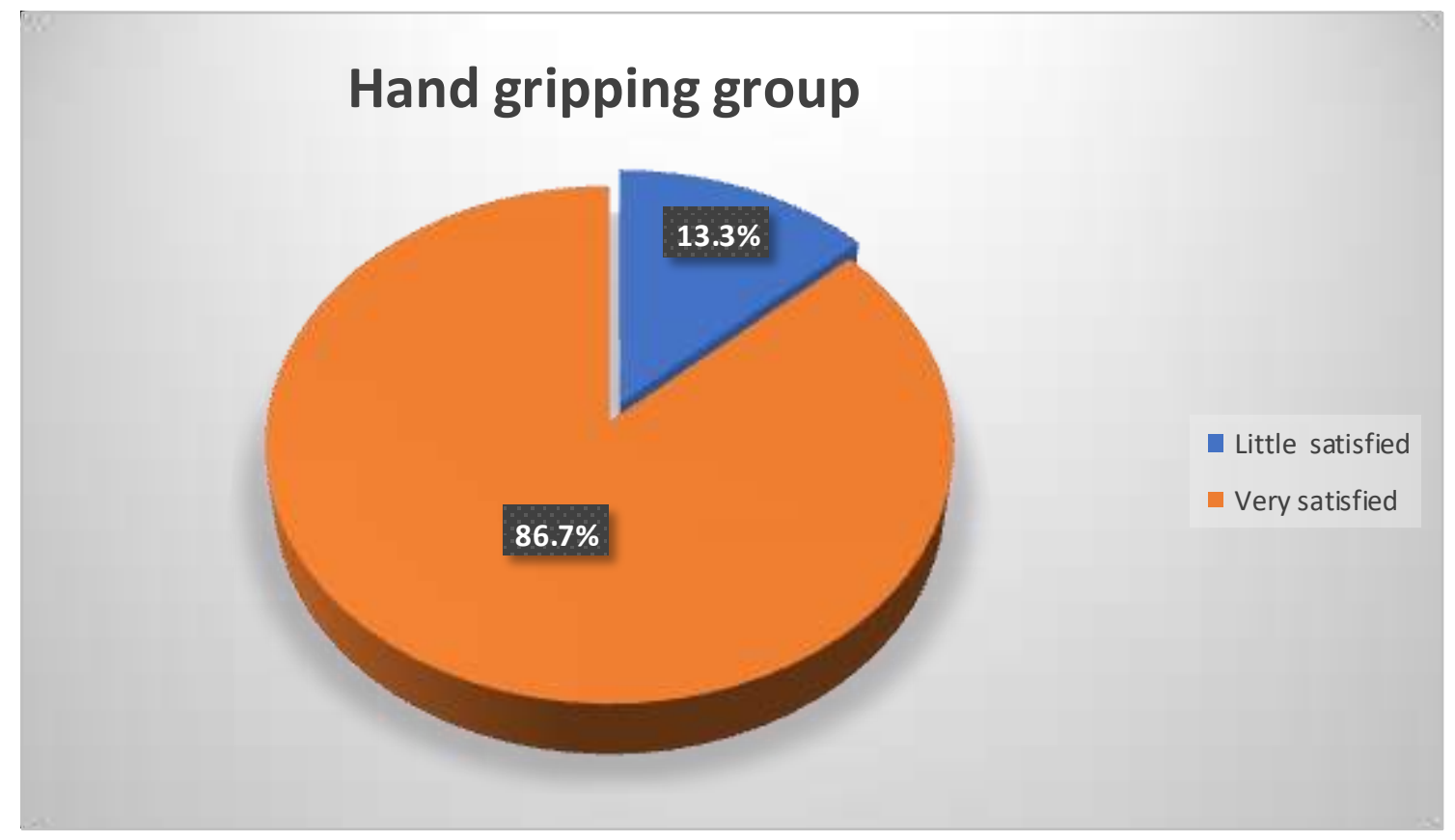

Figure (1):Distribution of the studied children according to their satisfaction level with the effect of hand griping technique on reducing vasovagal symptoms associated with vein puncture $(n=30)$. 


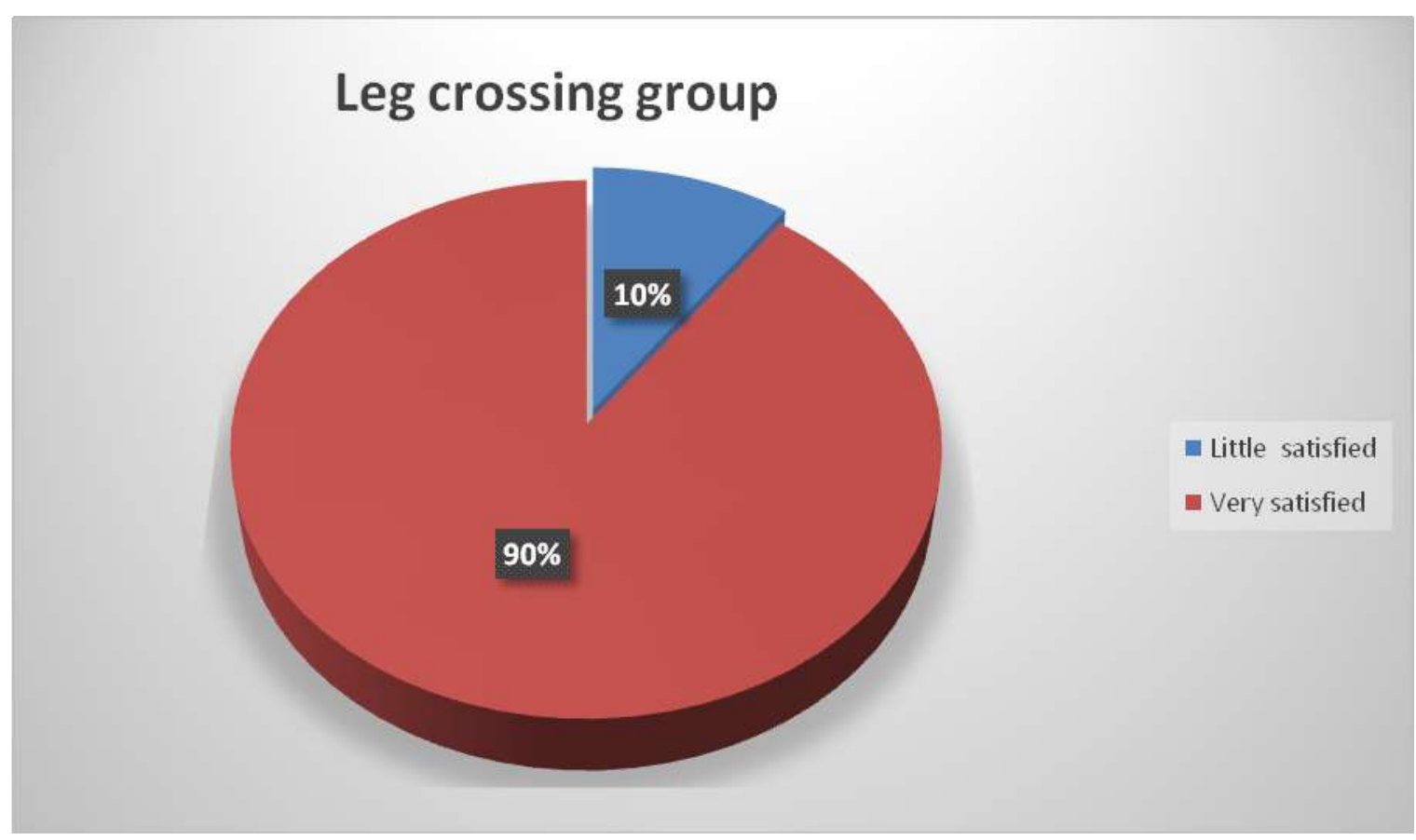

Figure (2):Distribution of the studied children according to their satisfaction level with the effect of leg crossing technique on reducing vasovagal symptoms associated with vein puncture $(\mathbf{n}=\mathbf{3 0}$

\section{Discussion:}

According to characteristics of the studied children, the current study revealed that, age of half and more of the studied children was ranged from $8-<10$ years $(\overline{\boldsymbol{x}} \pm$ S.D $10.7 \pm 2.34,10.4 \pm 3.60$ and11.3 \pm 2.91$)$. Also, around two thirds of them were males. Moreover, around two thirds of them were at primary.

These findings were in an agreement with Fathalla \& Ghoneim, (2018) who conducted a study about "Leg crossing and hand-griping interventions: it's effect on reducing of vasovagal symptoms associated with vein puncture in pediatric patients" who reported that the majority of children were school aged $\left(\overline{\boldsymbol{x}} \pm_{\text {S.D }} 12.32+4.68\right)$. But not similar as regard gender of the studied children, as they revealed that the majority of children were females.
As regards residence of the studied children, the result of the present study illustrated that, half and more of the studied children living in urban areas. This finding was in an accordance with Hassanein \& Deif, (2020) who conducted a study about "Effect of customized venipuncture nursing technique on selected responses and insertion difficulty among patients with blood disorders" and reported that $56.7 \%$ of them were living in urban areas.

The finding of the present study indicated that, there was no significant difference between all medical data of the studied children $(\mathrm{p}=>0.05)$. Where, around half of the studied children had pneumonia. This finding was in the same line with Alizadeh et al., (2016) who conduct study about "The role of acute physical maneuver in preventing vasovagal syncope: a randomized clinical trial" and reported hospitalized children had respiratory problems. 


\section{Effect of Leg Crossing and Hand Griping Techniques on Reducing Vasovagal Symptoms}

\section{Associated with Vein Puncture in Pediatric Patients}

The finding of the present study indicated that, there was no significant difference between all medical data of the studied children $(\mathrm{p}=>0.05)$ related to vein puncture. Most of them had vein puncture at hand for intravenous cannulation. From point of view of the researcher this might be due to the hand is most practical site for intravenous cannulation. This study finding was supported by Fathalla \& Ghoneim, (2018) who reported that the most frequently punctured site was forearm veins. And concerning type of vein access, peripheral intravenous cannuluation was the most frequent type of vein access in the three groups.

For problems associated with vein puncture, results of the current study reported that about one third of studied children had pain at the puncture site. This finding was in contrast with Galena, (2015) who conduct study about " Complications occurring from diagnostic venipuncture" and reported that minor bruising and hematoma were fairly common, involving $12.3 \%$ of vein punctures, with minor bruising being the most common reaction.

This finding agreed with Português, (2021) who conducted a study about “ Peripheral venipuncture: comprehension and evaluation of nursing practices". It was reported there was no serious local reactions (e.g.as cellulitis or phlebitis).

The findings of the present study showed that, there was highly statistical difference between leg crossing group, griping group and control group related to all physiological measurements immediately before and after vein puncture. As evidence, the heart rate, respiration and blood pressure were in normal ranges in children in leg crossing group and hand griping group post vein puncture as compared to control group.
From the researcher point of view this might be due to that leg crossing technique considered effective strategy during vein puncture.

These study findings contradicted with Adlakha et al., (2018) who conducted a study about "Association between baseline blood pressures, heart rates, and vasovagal syncope in children and adolescents". It was reported that there were no statistical significant differences between cases and controls related to systolic blood pressure $(\mathrm{p}=0.003)$

The findings of the present study showed that, there was highly significant difference between leg crossing group, hand griping group and control group related to total vasovagal signs and symptoms associated with vein puncture pre and post technique $(\mathrm{p}=<0.01)$. Children in leg crossing group exhibited less frequent vasovagal symptoms on post technique than control group. On the other hand, had griping group exhibited less frequent vasovagal symptoms on post technique than control group.

These study findings were consistent with Fathalla \& Ghoneim, (2018) who illustrated a comparison of vasovagal symptoms among leg crossing, hand griping and routine care groups. It was obvious that children in leg-crossing group exhibited less frequent vasovagal symptoms during vein puncture than control group (dizziness $=16 \%$, pallor $=12 \%, \quad$ bradycardia $=32 \%$, hypotension $=32 \%$, nausea $=8 \%$, abdominal discomfort $=4 \%$, sweating $=16 \%$, seeing black dots $=48 \%$ and blurred vision $=20 \%$ ). On the other hand, hand gripping group exhibited less frequent vasovagal symptoms during vein puncture (bradycardia $=40 \%$, hypotension $=40 \%$ and sweating $=20 \%$ ). In addition, there were statistically significant differences between children in leg-crossing, 


\section{Reda Abdel-Mohsen, Wafaa El-Sayed, Faten Shafik andHanan Nabawy}

and control groups regarding vasovagal symptoms (dizziness, pallor, bradycardia, hypotension, nausea, abdominal discomfort, sweating, seeing black dots and blurred vision: $\mathrm{p}$ value $<0.001)$.

The results of the present study showed that, there was highly significant difference between leg crossing group, griping group and control group related to total fear level pre- and post- technique at $(\mathrm{p}=<0.01)$. there was highly significant difference between leg crossing group, griping group and control group related to total fear level pre- and post- technique at $(p=<0.01)$. As regard, children in all groups of the study had a high fear level in pre technique, while children in leg crossing and hand griping group had lower fear level than children in control group pot technique .From the researcher point of view this might be duo to effect of hand griping and leg crossing techniques help children to be more relaxed and decreasing fear during vein puncture.

These results agreed with Petronella, (2017) who conduct a study in "Comparison of children's venipuncture fear and pain: randomized controlled trial of mela and j-tip needleless injection system" and reported that the procedural pain scores were significantly lower in the EMLA group ( local anesthetic ) (mean score $1.63+1.659$ ) vs. the J-Tip group (Needleless Injection) $(2.99 \pm 2.586 ; \quad \mathrm{p}<$ 0.001). Post-procedure fear scores were significantly lower than pre-procedure fear scores in both treatment groups $(p<0.002)$, but there was no difference in fear scores between the two treatment groups $(p=0.314)$.

The result of the present study revealed that most hand griping group very satisfied about hand-griping technique. This could help to prevent fainting and reduce pain during vein puncture, respectively. Also, majority of them were very satisfied about steps of hand -griping technique. They felt that it was easy to perform hand-griping technique which helped to reduce pain during vein puncture. From the researcher point of view this might be due to hand griping technique was simple, easy to perform and more effective technique in decreasing vasovagal signs and symptoms associated with vein puncture.

This finding was supported by Vimala et al., (2018) who conducted a study entitled "Effect of leg crossing and muscle tensing technique on pain among children undergoing vein puncture". It was reported that the majority of children were satisfied with the effect of hand-gripping (83\%) techniques on reducing the vasovagal symptoms.

The results of the present study showed that all children in the leg crossing group were very satisfied about leg crossing technique. Perhaps, it was easy to perform and can be repeated again with hand gripping technique, respectively. Also, the majority of them were very satisfied about leg crossing technique because it helps to prevent fainting. Furthermore, their general health condition after vein puncture was excellent with leg crossing technique.

This finding was consistent with McIntyre et al., (2018). They reported that approximately all children were satisfied of the effect of the leg-crossing (90\%) techniques in reducing the vasovagal symptoms.

\section{Conclusion:}

Leg crossing and hand griping techniques were associated with decrease in vasovagal symptoms of children undergoing vein puncture and experienced fewer numbers of vasovagal symptoms as compared to children in control group. Children in the 
intervention groups were satisfied with the implemented techniques for its effect on reducing vasovagal symptoms associated with vein puncture.

\section{Recommendation:}

- Leg crossing and hand griping techniques can be integrated as a part of routine daily care for children who have a past history of vasovagal symptoms during vein puncture.

- In-service nursing educational training programs about a leg crossing and hand griping techniques are necessary for children undergoing vein puncture.

- Further studies are highly suggested including a larger sample size.

- Suggest non pharmacological interventions namely leg crossing and hand griping techniques to reduce child pain and fear.

- Close supervision of children pre/post vein puncture.is important to detect any vasovagal signs and symptoms

\section{Acknowledgements:}

We would like to thank all children in the study in Benha University Hospital and Benha Teaching Hospital for their help and cooperation during the study period and appreciate the great efforts of the supervisors in this work.

\section{References:}

Adlakha, H., Gupta, R., Hassan, R. \& Kern, J. H. (2018). Association between baseline blood pressures, heart rates, and vasovagal syncope in children and adolescents. Cureus. 10(1):205-230

Alizadeh, A., Peighambari, M., Keikhavani, A., Emkanjoo, Z., Rad, A., \&Ghadrdoost, B.( 2016). The role of acute physical maneuver in preventing vasovagal syncope: a randomized clinical trial. Clinic cardia electrophysiology.1 (1): 5348.
Brignole, M., Moya, A. \& de Lange, FJ. (2018). Isometric arm counter-pressure maneuvers to abort impending vasovagal syncope, Europian Heart Journal. 39(21): 83.

Dalton, T. \& Wang, N. E. (2017). Pediatric Syncope: Current status of diagnostic evaluation and management. Pediatric emergency medicine reports. 22(5), 13-15.

Fathalla, A. \& Ghoneim, A. (2018). Leg crossing and hand-griping interventions: its effect on reducing of vasovagal symptoms associated with venipuncture in pediatric patients. IOSR Journal of Nursing and Health Science.7 (6). 85

Galena, H. (2015). Complications occurring from diagnostic venipuncture.Retrievedfrom https:// pubmed .ncbi.nlm .nih.gov/ 1578208/ accesed on 12/1/2021 10.00pm

Hassanein, S. \& Deif, H. (2020). Effect of customized venipuncture nursing technique on selected responses and insertion difficulty among patients with blood disorders. Egyptian Nursing Journal.17 (1).23-25.

McMurtry, M. S., Archer, S. L., Cushman, M., Goldenberg, N., Goldhaber, S. Z. \& Zierler, B. K. (2011). Management of massive and submassive pulmonary embolism, iliofemoral deep vein thrombosis, and chronic thromboembolic pulmonary hypertension: a scientific statement from the American

Heart Association. Circulation, 123(16), 1788-1830.

McIntyre, L., Wanderski, S., Graef, D., Woessner, L. \& Baker R. (2018). Randomized trial evaluating the effectiveness of a leg crossing and muscle tensing technique on decreasing vasovagal symptoms among pediatric and young adult patients undergoing peripheral IV catheter insertion. Journal of Pediatric Nursing. 38(1):53-56. 
Naganna, P., Hussain, N. M. \& Hussain, N. (2020). Approach to the pre-school child with sudden loss of consciousness. Pediatrics and Child Health. 30(9): 333

Petronella, S. (2017). Comparison of children's venipuncture fear and pain: randomized controlled trial of EMLA® and JTip Needleless Injection System. Journal of Pediatric Nursing. 37(1):91-96

Português, E. (2021). Peripheral venipuncture: comprehension and evaluation of nursing practices. http://dx.doi.org/10.1590/1980-265x-tce2018-0018 accessed on 9-8-2020

Shen, W.K., Sheldon, R. \& Benditt, D.(2017). Guideline for the evaluation and management of patients with syncope: A report of the american college of cardiology/american heart association task force on clinical practice guidelines, and the heart rhythm society. Journal of the American College of Cardiology. 70(5):39-110.

Vimala, T., Rupali ,S., Nisha ,N., Mary, A.,\& Vaishali, J. (2018). Effect of Leg Crossing and Muscle Tensing Technique on Pain among Children Undergoing Venipuncture. Indian Journal of Public Health Research \& Development. 11 (4): 482-485

Zhang, J., Tang, H., Wang, Y., Cai, H., Zou, R., Wang, S. \& Wang, C. (2020). Clinical values of creatine kinase and its isoenzymes in children and adolescents with vasovagal syncope. Nutrition, Metabolism and Cardiovascular Diseases. 30(10):18481854. 
تأثير تقنيات تقاطع السلق وقبضة اليد على تقليل الأعراض الوعائية المرتبطتبالوخز الوريدي في الأطفال المرضى رضا عبدالمحسن عوض- وفاء السبد عوده - فاتن شفيق محمود - حنان نبوي الاعصر

وخز الوريد هو واحد من الإجراءات التشخيصية والعلاجية الأكثر استخداما على نطاق واسع في

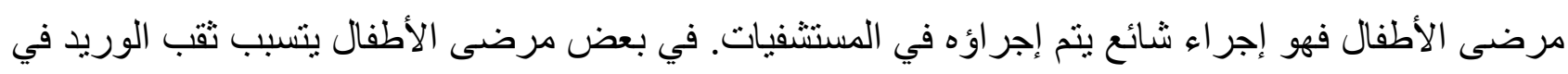

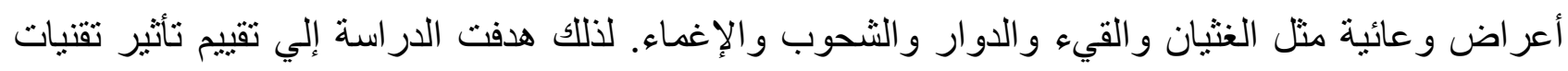

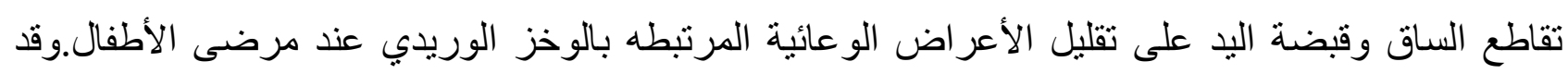

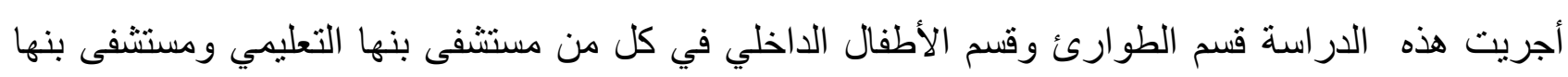

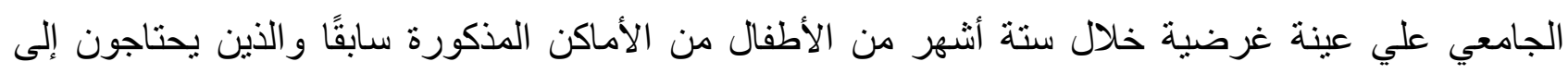
وصول وريدي لأي سبب من الأسباب. حيث خلصت الدراسة الي نجاح تقنية تقاطع الساق وقبضة اليد في تقليل

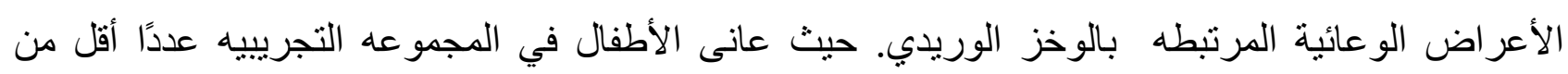

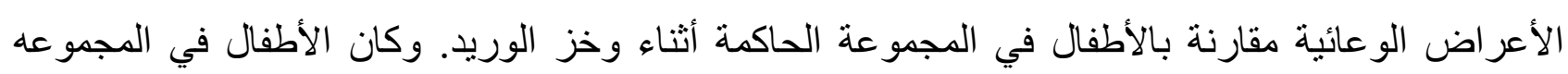

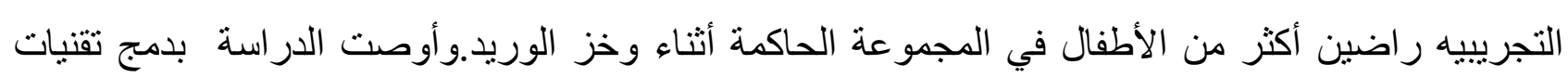

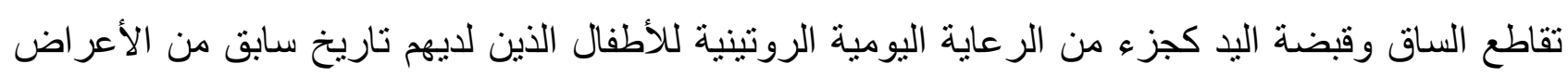
الوعائية المرتبطه بالوخز الوريدي. 